\title{
Vegetative Compatibility Groups of Fusarium oxysporum f. sp. cepae from Onion in Colorado
}

\author{
C. E. Swift, Colorado State University, Cooperative Extension, Grand Junction 81502-5028; and E. R. Wickliffe, \\ Former Graduate Student, and H. F. Schwartz, Professor, Department of Bioagricultural Sciences and Pest \\ Management, Colorado State University, Fort Collins 80523-1177
}

\begin{abstract}
Swift, C. E., Wickliffe, E. R., and Schwartz, H. F. 2002. Vegetative compatibility groups of Fusarium oxysporum f. sp. cepae from onion in Colorado. Plant Dis. 86:606-610.

Nineteen isolates of Fusarium oxysporum f. sp. cepae recovered from diseased onions growing in the western, southern, and northern regions of Colorado were placed into vegetative compatibility groups (VCGs) based on pairing of complementary mutants. Pathogenic isolates from these regions were cultured on variations of potassium chlorate (1.5 or 3.0\%) mutation media, potato dextrose agar (PDA), and minimal medium (MM) supplemented with Lasparagine and L-threonine. Chlorate PDA and 3\% chlorate MM with L-threonine did not generate the nitrate nonutilizing (nit) mutants required, while MM with L-asparagine (1.5 and $3 \%$ chlorate) and MM with L-threonine (1.5\% chlorate) generated complementary nit mutants required for compatibility pairings. Five VCGs of $F$. oxysporum cepae were identified. One VCG was present in all three regions of Colorado examined. Four VCGs were restricted to either western or eastern Colorado. Additional sampling and evaluation of a more diverse collection of F. oxysporum cepae isolates from other regions of onion production is needed to determine the diversity of this pathogen. Such information could assist in breeding for resistance to $F$. oxysporum cepae.
\end{abstract}

Additional keywords: Fusarium wilt, Fusarium yellows, Fusarium basal rot of onion

Fusarium basal rot of onion is caused by Fusarium oxysporum Schlechtend.:Fr. f. sp. cepae (H. N. Hans.) W. C. Snyder \& H. N. Hans. (35). As early as 1920, researchers reported significant losses from Fusarium wilt in onion fields and storage sheds near Grand Junction and Delta, CO (26). More than $85 \%$ of the onions produced in Colorado are dry storage onions (Allium cepae L.), with an annual value of 40 to 50 million dollars (7). Onion production in Colorado occurs in three main growing regions that are located approximately 250 $\mathrm{km}$ apart. The western, southern, and northeastern regions comprise 20, 25, and 55 percent of the onion acreage in Colorado, respectively. The total area of onion production in Colorado ranges between 4,000 and 6,000 ha. Approximately 85 to $90 \%$ of the acreage is planted to onion seed, and the remaining area is planted to transplants for the early and fresh markets (33). Statewide yields of approximately 45 t/ha can be significantly reduced by adverse environmental factors or pathogens such as $F$. oxysporum cepae $(13,34)$.

Corresponding author: H. F. Schwartz

E-mail: hfspp@lamar.colostate.edu

Accepted for publication 24 January 2002.

Publication no. D-2002-0325-03R

(C) 2002 The American Phytopathological Society
Fusarium species are some of the most important plant pathogens in the world (28). F. oxysporum Schlechtend. emend. W. C. Snyder \& H. N. Hans., a common soilborne Fusarium sp. with a worldwide distribution, has no known sexual stage. As a species, this organism probably causes more economic damage than any other plant pathogen (8), and has been shown to constitute as much as 80 to $90 \%$ of the total fungal microflora in the rhizosphere of several agricultural crops (12). F. oxysporum is responsible for wilt and cortical rot diseases of more than 100 economically important plant hosts (4).

Seventeen years ago, Puhalla (31) developed a method by which isolates within different formae speciales of $F$. oxysporum could be classified in vegetative compatibility groups (VCGs). VCGs also can be used to compare isolates among formae speciales of $F$. oxysporum (29). Vegetative compatibility provides a means of characterizing variation based on the genetics of the fungus rather than on the host-pathogen interaction $(8,25)$. Isolates in a VCG often share pathological and physiological attributes as well as geographic origins. Consequently, vegetative compatibility has been used to study the origins of and relatedness among plant pathogenic fusaria (30). Pathogenic isolates of $F$. oxysporum in the same VCG are presumed to be clones, even if they are geographically isolated from each other. The loci and al- leles that define VCGs are presumed to be selectively neutral with respect to traits such as pathogenicity and vegetative viability (24). Research on VCGs for $F$. oxysporum cepae is lacking other than limited work by Yoo et al (39).

To determine VCGs of fungal isolates, various media augmented with potassium chlorate are used to produce nitrate nonutilizing (nit) mutants, which mutate at different loci associated with the nitrateassimilation pathway. These media include potato-dextrose chlorate $(2,16,20,38)$, potato-sucrose chlorate (6), Czapek Dox chlorate $(3,27)$, and minimal medium chlorate (32). Bosland and Williams (5) used potato-sucrose agar, cornmeal agar with dextrose, potato-dextrose agar (PDA), and potato-carrot-dextrose agar media, each amended with potassium chlorate (11). Lasparagine typically is added to the chlorate medium to provide a source of carbon, although L-threonine (15) and L-glutamine (27) have been used.

The objective of this study was to determine the regional diversity among Colorado isolates of $F$. oxysporum cepae based on VCGs, and to identify the most effective chlorate media for generation of nit mutants of $F$. oxysporum cepae for VCG complementation pairings (36).

\section{MATERIALS AND METHODS}

Eighteen isolates of $F$. oxysporum cepae were obtained from onions infected with Fusarium basal rot collected in the fall of 1999 in the western region (Mesa, Delta, and Montrose Counties) of Colorado. Isolates were evaluated for cultural characteristics, absence of contamination by other fungal species, and conidial morphology typical of $F$. oxysporum prior to pathogenicity testing as described below. Six additional isolates of $F$. oxysporum cepae from the cryogenic collection of $\mathrm{H}$. F. Schwartz at Colorado State University also were evaluated to determine if isolates collected from onion fields in eastern (Weld County) and southern (Otero County) Colorado from 1988 to 1998 were related to the isolates from western Colorado. The nit mutants of these 24 isolates were generated by Swift (36) and Wickliffe (37). Of the 24 isolates, 19 produced nit mutants required for complementary pairings and placement into VCGs.

Yellow Sweet Spanish onions (an unknown cultivar, but susceptible to all iso- 
lates of $F$. oxysporum cepae in this study) were purchased from a grocery store. The onions were surface sterilized for $60 \mathrm{~s}$ with $90 \%$ methanol, the outer two scales were removed, and the cross section of each bulb was sliced aseptically to a thickness of $2 \mathrm{~mm}$ using a Progressive Multi-slicer (Progressive International Corp., Seattle, WA). A $10 \%$ bleach solution $(0.525 \%$ sodium hypochlorite) was used to sterilize the Multi-slicer. Onion slices were placed aseptically in sterile plastic petri dishes (100 by $15 \mathrm{~mm}$ ).

Surface-disinfected, dried tissue from the infected basal plate and roots of the individual onion samples collected in western Colorado was pulverized under aseptic conditions to produce inoculum. Sterile distilled water $(5 \mathrm{ml})$ was added to each gram of pulverized tissue. A 1-ml aliquot of the resulting suspension was spread over the onion slices. F. oxysporum colonies that developed on onion slices at $25^{\circ} \mathrm{C}$ after 5 to 7 days of incubation on a lab bench under continuous fluorescent light provided evidence of isolate pathogenicity according to the methodology of Abawi and Lorbeer (1). Spores of pathogenic isolates identified as $F$. oxysporum by microscopic examination were transferred to complete medium (CM; 10) and grown for 4 days at $25^{\circ} \mathrm{C}$ under continuous fluorescent lights, after which hyphal tips were transferred to chlorate media.

Chlorate media consisted of minimal medium (MM) supplemented with either 1.5 or $3 \%$ potassium chlorate $\left(\mathrm{KClO}_{3}\right)$. Inadequate sectoring and lack of complementary nit mutants were observed for some isolates; therefore, various chlorate media were evaluated to determine which was most effective for generating complementary nit mutants needed to determine VCGs of the isolates of $F$. oxysporum cepae.

PDA and MM supplemented with $1.5 \%$ or $3.0 \% \mathrm{KClO}_{3}$ (wt/vol) were used as the chlorate media. MM was supplemented with L-asparagine or L-threonine at 1.6 or $2.3 \mathrm{~g} \mathrm{liter}^{-1}$, respectively. Three $1-\mathrm{mm}^{3}$ pieces of agar containing hyphae of the isolate were placed on each 100-by-15-mm plastic disposable petri dish. Three petri dishes of each medium/chlorate level were used per isolate for a total of 18 plates per isolate. The petri dishes were placed under continuous fluorescent light at $25^{\circ} \mathrm{C}$ for at least 2 days. The isolates incubating on chlorate media were checked every other day for sectoring. If a colony with sparse aerial mycelium developed, a hyphal tip from the sector was transferred to a 60-by15-mm petri plate containing $\mathrm{MM}$ and cultured for at least 2 days under continuous fluorescent lights at $25^{\circ} \mathrm{C}$. Isolates that retained their sparse characteristics were considered nit mutants. Isolates that reverted to a dense aerial mycelium on MM were considered chlorate-resistant, nitrateutilizing isolates and discarded.
Phenotyping media consisted of MM supplemented with ammonium tartrate $\left(\mathrm{C}_{4} \mathrm{H}_{12} \mathrm{~N}_{2} \mathrm{O}_{6}\right)$, nitrate $\left(\mathrm{NO}_{3}{ }^{-}\right)$, nitrite $\left(\mathrm{NO}_{2}{ }^{2-}\right)$, and hypoxanthine (HX). Four mutants were placed on each 100 -by-15-mm petri dish of phenotyping medium and incubated at $25^{\circ} \mathrm{C}$ under continuous fluorescent lights. Isolates were evaluated within 3 to 4 days. Colonies with abundant aerial mycelium (fluffy) were considered as having a "+" growth; colonies with sparse, transparent mycelium were considered as having a "-" growth. The nit mutants were characterized as nitl (unable to utilize nitrate), nit3 (unable to utilize nitrate or nitrite), or NitM (unable to utilize nitrate, hypoxanthine, or uric acid) (27). One NitM and nitl were selected from each isolate for VCG comparison. When a NitM was not generated, a nit3 was selected. When the combination of NitM and nitl, or nit1 and nit3, was not generated, comparisons were not conducted. Of the 24 isolates examined in this study, 33\% (8) did not generate NitM mutants.

Vegetative compatibility testing. The nit mutants were paired in all possible combinations in two tests. Isolates were paired on 100-by-15-mm MM petri dishes in the first test and on 96-well tissue culture plates containing $\mathrm{MM}$ in the second test to determine the compatibility of the isolates and to classify each isolate into a VCG. A total of 21 and 25 pairs of mutants were compared in the first and second tests, respectively. The number of isolates used in the two trials was different because of the addition of isolates generated over the course of the research project and the loss of isolates due to their reversion to a wild strain.

Pairings of isolates on 100-by-15-mm petri dishes of MM was accomplished by transferring $1-\mathrm{mm}^{3}$ pieces of $\mathrm{MM}$ agar containing hyphae of the mutant, as described by Correll et al. (10). Pairings of isolates in the 96-well tissue culture plates was accomplished by transferring a $1-\mathrm{mm}^{3}$ of MM agar containing hyphae of the mutant to a 60-by-15-mm petri dish containing CM. The inoculated dishes of CM were maintained at $25^{\circ} \mathrm{C}$ under fluorescent lights until the surface of each plate was covered with aerial mycelium of the mutant. A $2 \%$ solution of Tween $60(2 \mathrm{ml})$ was added to the plate and the colony gently scraped with a sterile scalpel. Two microliters of the suspension of fungal tissue of the mutant was placed in the appropriate wells of the 96-well tissue culture plate containing MM, followed by an aliquot of the paired mutant.

Inoculated petri dishes and tissue culture plates were incubated at $25^{\circ} \mathrm{C}$ under continuous fluorescent lights and evaluated as early as 5 days after inoculation. Isolates were considered to be vegetatively compatible if the complementation of the nit mutants resulted in the formation of dense aerial growth at the zone of the anastomosing mycelia in the petri dishes, or as dense mycelial growth in the 96-cell tissue culture plates (i.e., apparent heterokaryon compatibility).

\section{RESULTS}

A total of 358 mutants of $F$. oxysporum cepae that were generated on the chlorate media were evaluated in this study (see Table 1). Media supplemented with $3 \%$ chlorate generated 185 mutants $(52 \%)$, while media supplemented with $1.5 \%$ chlorate generated 173 mutants $(48 \%)$. The relative frequency of mutants produced was 66,6 , and $28 \%$ for nit1, nit3, and NitM phenotypes, respectively. The 3 and $1.5 \%$ PDA chlorate media produced the greatest number of mutants (91 and 62, respectively), but the lowest percentage of NitM mutants (10 and 15\%, respectively).

Of the mutants generated on the $3 \%$ chlorate $\mathrm{MM} / \mathrm{L}$-asparagine, $55 \%$ were nit1 mutants and $43 \%$ were NitM mutants. Of the mutants generated on the $1.5 \%$ chlorate $\mathrm{MM} / \mathrm{L}$-asparagine, $50 \%$ were nit 1 and $46 \%$ were NitM mutants. The percentage of nit1 and NitM mutants generated on the MM/Lthreonine chlorate medium were 69 and $25 \%$ on $3 \%$ chlorate, respectively, and 35 and $45 \%$ on $1.5 \%$ chlorate, respectively. Of the 24 isolates, $8(33 \%)$ did not generate NitM mutants on the different chlorate

Table 1. Generation of 358 mutants from 24 isolates of Fusarium oxysporum f. sp. cepae on 1.5 and $3.0 \%$ potassium chlorate mutation media of potato dextrose agar or of minimal media supplemented with L-asparagine or L-threonine

\begin{tabular}{|c|c|c|c|c|}
\hline \multirow[b]{2}{*}{ Mediuma $^{\text {a }}$} & \multicolumn{4}{|c|}{ Mutation frequency, number $(\%)$} \\
\hline & nit 1 & nit 3 & Nit M & Total \\
\hline \multicolumn{5}{|l|}{$1.5 \% \mathrm{KclO}_{3}$ plus: } \\
\hline PDA & $53(85)$ & $0(0)$ & $9(15)$ & $62(17)$ \\
\hline $\mathrm{MM} /$ threonine & $21(35)$ & $12(20)$ & $27(45)$ & $59(16)$ \\
\hline MM/asparagine & $26(50)$ & $2(4)$ & $23(46)$ & $52(15)$ \\
\hline Subtotal: & $100(28)$ & $14(4)$ & $59(16)$ & $173(48)$ \\
\hline \multicolumn{5}{|l|}{$3.0 \% \mathrm{KClO}_{3}$ plus: } \\
\hline PDA & $78(86)$ & $4(4)$ & $9(10)$ & $91(26)$ \\
\hline MM/threonine & $26(69)$ & $2(6)$ & $9(25)$ & $37(10)$ \\
\hline MM/asparagine & $31(55)$ & $1(2)$ & $25(43)$ & $57(16)$ \\
\hline Subtotal: & $135(38)$ & $7(2)$ & $43(12)$ & $185(52)$ \\
\hline Total: & $236(66)$ & $21(6)$ & $102(28)$ & $358(100)$ \\
\hline
\end{tabular}

${ }^{a} \mathrm{PDA}=$ potato dextrose agar, $\mathrm{MM}=$ minimal medium. 
media. Four isolates produced only one NitM mutant.

Through complementary pairings of Nit mutants, five VCGs were identified (Table 2). Isolates 21 and 23 were incompatible with all other isolates and were not assigned a VCG code. The three other VCGs identified were assigned VCG codes 0421, 0422, and 0423 in accordance with the Puhalla numbering system (31).

\section{DISCUSSION}

In the 1980s, a method was proposed by Puhalla (31) in which isolates of $F$. oxysporum were identified and classified based on VCGs. This system recommended vegetatively compatible isolates be given a VCG code with the first three digits corresponding to the host specialization, or forma specialis, and one or two more digits corresponding to individual VCGs within that forma specialis. Puhalla assigned 16 specific numbers to VCGs of various formae speciales at that time. Since then, over 180 VCGs have been reported for 47 formae speciales of $F$. oxysporum $(18,19)$. Based on the study of two Japanese isolates, Y-2 and Y-12, Yoo et al. (39) identified one VCG of $F$. oxysporum $\mathrm{f}$. sp. cepae, the causal agent of Fusarium basal rot of onion. These two isolates were vegetatively compatible; consequently, the four-digit numerical code 0420 was assigned (19). Research in Colorado has subsequently identified five VCGs (Table 2 ) for this forma specialis. Three of these
VCGs (VCG 1, 2, and 3) have been tentatively numbered 0421, 0422, and 0423. Of the 19 isolates evaluated in this study, 2 were not compatible with any other isolates. Consequently, they were placed in VCG 4 and 5, but were not assigned a four-digit numerical code based on the recommendations of Kistler et al. (22) that single-member VCGs not be numbered. The final decision on assignment of a VCG code is dependent upon the VCG coordination committee. The Colorado VCGs eventually will be compared with the Japanese VCG to determine their relationship.

Isolates within a forma specialis are genetically similar, probably originating from a single pathogenic genotype or clonal origin. Kistler (21) proposed that a VCG within a population of $F$. oxysporum indicates a distinct clonal lineage. Harveson and Rush (14) found that VCGs of F. oxysporum f. sp. betae represented distinct isolated populations indigenous to their respective areas. Woo et al. (38) and Bosland and Williams (5), however, reported that the formae speciales they were investigating did not exhibit a correlation between VCG and geographical origin. Four of the Colorado VCGs were found to be limited in their geographical range.

VCG 1 was present on onion bulbs growing in two western and two eastern counties of Colorado. VCG 2 was present only in Delta County, and VCG 3 was located only in Mesa County. VCGs 4 and

Table 2. Isolate number, geographic origin (county), year the isolate was collected, and vegetative compatibility group (VCG) of 19 isolates of Fusarium oxysporum f. sp. cepae collected from diseased onion plants in Colorado

\begin{tabular}{lllcl}
\hline Isolate & County & Year & VCG $^{\mathbf{b}}$ & VCG code $^{\mathbf{c}}$ \\
\hline 22 & Montrose & 1999 & 1 & 0421 \\
25 & Delta & 1999 & 1 & 0421 \\
27 & Delta & 1999 & 1 & 0421 \\
28 & Delta & 1999 & 1 & 0421 \\
FOC 1 & Weld & 1992 & 1 & 0421 \\
FOC 4 & Otero & 1988 & 1 & 0421 \\
FOC 8 & Delta & 1993 & 1 & 0421 \\
FOC 201A & Weld & 1998 & 1 & 0421 \\
FOC 201D & Weld & 1998 & 1 & 0421 \\
FOC 204A & Weld & 1998 & 1 & 0421 \\
31 & Delta & 1999 & 2 & 0422 \\
32 & Delta & 1999 & 2 & 0422 \\
41 & Mesa & 1999 & 3 & 0423 \\
42 & Mesa & 1999 & 3 & 0423 \\
47 & Mesa & 1999 & 3 & 0423 \\
48 & Mesa & 1999 & 3 & 0423 \\
50 & Mesa & 1999 & 3 & 0423 \\
21 & Montrose & 1999 & 4 & not assigned \\
23 & Montrose & 1999 & 5 & not assigned \\
\hline
\end{tabular}

${ }^{a}$ Regions of onion production in Colorado: northeastern (Weld County), southeastern (Otero County), and western (Delta, Mesa, and Montrose Counties).

${ }^{\mathrm{b}}$ Potato-dextrose chlorate agar (CPDA) and chlorate minimal medium (CMM) were used to generate nit mutants. CMM was supplemented with L-asparagine or L-threonine at 1.6 or $2.3 \mathrm{~g} \mathrm{liter}^{-1}$. All media were supplemented with 1.5 or $3.0 \% \mathrm{KClO}_{3}(\mathrm{wt} / \mathrm{vol})$. Nit mutants were paired in all possible combinations to determine the compatibility and VCG classification of each isolate. Complementation pairings were made between nitl and NitM mutants, or nit1 and nit3 mutants, based on availability. Isolates were considered to be vegetatively compatible if the complementation of the nit mutants resulted in the formation of a heterokaryon with dense aerial growth.

c Vegetatively compatible isolates are given a VCG code consisting of a four- or five-digit number, with the first three digits corresponding to host specialization, or forma specialis, and the following digits corresponding to individual VCGs within that forma specialis.

5 were collected from onion bulbs in Montrose County. Table 2 provides specifics on these VCGs.

The genetic relatedness and possible evolutionary linkages among the Colorado VCGs, as well as VCGs from other oniongrowing areas around the world, need to be examined. Comparisons of mitochondrial DNA, restriction fragment length polymorphism haplotypes, and other genetic fingerprinting techniques would help determine the relative genetic distances among these VCGs and their clonal relationship (17,23).

Although a more thorough study of the population of VCGs of $F$. oxysporum $\mathrm{f}$. sp. cepae present in Colorado is required, the data at this time indicates this organism has been established in western Colorado for a longer period of time than in other Colorado onion-growing areas. The diversity of vegetative compatibility groups of $F$. subglutinans $\mathrm{f}$. sp. pini, the causal agent of pine pitch canker, is an excellent example to further explain this assumption (9).

$F$. subglutinans f. sp. pini has been established in Florida since the mid 1970s with 45 distinct VCGs of the organism classified. On the other hand, $70 \%$ of the California population, where the organism was first reported in 1986, consists of a single VCG. A single VCG predominates in this epidemic front. The lack of diversity of the California VCG population is indicative of an asexually reproducing pathogen that has been recently introduced (9). As a population ages, the diversity increases. A more exhaustive examination of the population of $F$. oxysporum $\mathrm{f}$. sp. cepae in Colorado may reveal a greater diversity of VCGs in northeastern or southern Colorado than has been currently found.

A better pathogenicity protocol for $F$. oxysporum f. sp. cepae on onion is necessary. Onion slices were used in this study to determine isolate pathogenicity. A pathogenicity protocol such as root clip inoculation might identify a set of differential cultivars that could be used to determine races of the organism. If cultivar differences were identified, differences in virulence might be found.

Complementary pairings in this study were done on both 100-by-15-mm petri dishes and 96-well tissue culture plates. Complementary pairings of nit mutants in petri dishes is time consuming, but these results are more distinct than those obtained with pairings in tissue culture plates. The dense aerial growth that develops is the location at which nit mutant colonies anastomose to form a heterokaryon. The point of actual heterokaryon formation cannot be observed when complementary pairings are made on 96-well tissue culture plates. This formation is obvious on petri dishes. In addition, the application of drops of an aliquot containing the mutant to a 96well plate is an exacting process. Con- 
tamination of neighboring wells is a possibility that might result in false positive readings.

Puhalla (31) and Puhalla and Spieth (32) report isolates of $F$. oxysporum and $F$. moniliforme sectored when cultured on MM containing $1.5 \% \mathrm{KClO}_{3}$ (MMC). $F$. oxysporum $\mathrm{f}$. $\mathrm{sp}$. niveum mutants are easily obtained on PDA containing $1.5 \% \quad \mathrm{KClO}_{3}$ (16). F. subglutinans f. sp. pini isolates from California, however, are not restricted on $1.5 \%$ MMC, but chlorate-resistant sectors are readily recovered from these isolates on $3 \%$ MMC. In contrast, the Florida isolates are readily recovered on 1.5\% MMC (9). According to Woo et al. (38), the relative frequencies of nit mutants of $F$. oxysporum f. sp. phaseoli varied based on the chlorate media used. The nit mutants recovered from PDA supplemented with $1.5 \%$ potassium chlorate were as follows: nit1 $=60$ to $86 \%$, nit3 $=4$ to $23 \%$, and $\mathrm{NitM}=0$ to $15 \%$. On MM supplemented with $1.5 \%$ potassium chlorate, the following percentages of mutants were recovered: nit1 $=58$ to $62 \%$, nit $3=5$ to $25 \%$, and $\mathrm{NitM}=0$ to $25 \%$. Bosland and Williams (5) used potato-sucrose (PS), cornmeal agar with dextrose (CMDA), PDA, and potato-carrot-dextrose agar (PCDA) media to generate mutants. Each was supplemented with potassium chlorate at $20 \mathrm{~g}$ liter-1. Their research indicated that $2 \%$ chlorate PDA and CMDA generated more sectors than chlorate PCDA.

To determine which chlorate media were most effective in generating mutants from Colorado isolates of $F$. oxysporum cepae, PDA, MM supplemented with L-asparagine at $1.6 \mathrm{~g} \mathrm{liter}^{-1}$ of distilled water, and MM supplemented with L-threonine at 2.3 $\mathrm{g} \mathrm{liter}^{-1}$ of distilled water were tested. Each was further supplemented with $\mathrm{KClO}_{3}$ at 1.5 and $3 \%$ (wt/vol). A total of 358 mutants were generated. In all, $33 \%$ of the isolates did not generate NitM mutants. An additional $16 \%$ produced only one NitM mutant each, and $6 \%$ of the mutants were nit3.

Chlorate PDA and 3\% chlorate MM with L-threonine did not generate the nit mutants required, whereas $\mathrm{MM}$ with Lasparagine (1.5 and 3\% chlorate) and MM with L-threonine (1.5\% chlorate) generated the necessary complementary nit mutants. The latter two chlorate media should be considered for use when generating nit mutants of $F$. oxysporum f. sp. cepae.

Transferring mutants to DM resulted in more reversions to the wild-type growth than when mutants were grown on MM (unpublished data). MM will be used in future trials when maintaining mutants of this pathogen in culture.

Isolates of the five Colorado VCGs reported in this article are maintained in the cryogenic collection of Howard F. Schwartz at Colorado State University. Representatives of each will be submitted for storage at internationally recognized fungal culture collections upon request by the VCG coordination committee and henceforth will be available for comparison by other researchers.

\section{LITERATURE CITED}

1. Abawi, G. S., and Lorbeer, J. W. 1965. Cultural variability and pathogenicity of Fusarium oxysporum f. sp. cepae. (Abstr.) Phytopathology 55:1051

2. Alves-Santos, F. M., Benito, E. P., Eslava, A. P., and Diaz-Minguez, J. M. 1999. Genetic diversity of Fusarium oxysporum strains from common bean fields in Spain. Appl. Environ. Microbiol. 65:3335-3340.

3. Blok, W. J., and Bollen, G. J. 1997. Host specificity and vegetative compatibility of Dutch isolates of Fusarium oxysporum f. sp. asparagi. Can. J. Bot. 75:383-393.

4. Booth, C. 1971. The Genus Fusarium. Commonwealth Mycological Institute, Kew, Surrey, England.

5. Bosland, P. W., and Williams, P. H. 1987. An evaluation of Fusarium oxysporum from crucifers based on pathogenicity, isozyme polymorphism, vegetative compatibility, and geographic origin. Can. J. Bot. 65:2067-2073.

6. Clark, C. A., Hoy, M. W., and Nelson, P. E. 1995. Variation among isolates of Fusarium lateritium from sweet potato for pathogenicity and vegetative compatibility. Phytopathology 85:624-629.

7. Colorado Agricultural Statistics. 2000. Annual Report, Colorado Department of Agriculture, Denver.

8. Correll, J. C. 1991. The relationship between formae speciales, races, and vegetative compatibility groups in Fusarium oxysporum. Phytopathology 81:1061-1064.

9. Correll, J. C., Gordon, T. R., and McCain, A. H. 1992. Genetic diversity in California and Florida populations of the pitch canker fungus Fusarium subglutinans f. sp. pini. Phytopathology 82:415-420.

10. Correll, J. C., Klittich, C. J. R., and Leslie, J. F. 1987. Nitrate nonutilizing mutants of Fusarium oxysporum and their use in vegetative compatibility tests. Phytopathology 77:1640-1646.

11. Cove, D. J. 1976. Chlorate toxicity in Aspergillus nidulans: The selection and characterisation of chlorate resistant mutants. Heredity 36:191-203.

12. Elias, K. S., Schneider, R. W., and Lear, M. M. 1991. Analysis of vegetative compatibility groups in nonpathogenic populations of Fusarium oxysporum isolated from symptomless tomato roots. Can. J. Bot. 69:20892094.

13. Everts, K. L., Schwartz, H. F., Epsky, N. D., and Capinera, J. L. 1985. Effects of maggots and wounding on occurrence of Fusarium basal rot of onions in Colorado. Plant Dis. 69:878-882.

14. Harveson, R. M., and Rush, C. M. 1997. Genetic variation among Fusarium oxysporum isolates from sugar beet as determined by vegetative compatibility. Plant Dis. 81:85-88.

15. Hawthorne, B. T., and Rees-George, J. 1996. Use of nitrate non-utilizing mutants to study vegetative incompatibility in Fusarium solani (Nectria haematococca), especially members of mating populations I, V and VI. Mycol. Res. 100:1075-1081.

16. Hopkins, D. L., Lobinske, R. J., and Larkin, R. P. 1992. Selection for Fusarium oxysporum f. sp. niveum Race 2 in monocultures of watermelon cultivars resistant to Fusarium wilt. Phytopathology 82:290-293.

17. Jacobson, D. J., and Gordon, T. R. 1990.
Variability of mitochondrial DNA as an indicator of relationships between populations of Fusarium oxysporum f. sp. melonis. Mycol. Res. 94:734-744.

18. Katan, T. 1999. Current status of vegetative compatibility groups in Fusarium oxysporum. Phytoparasitica 27:51-64.

19. Katan, T., and Di Primo, P. 1999. Current status of vegetative compatibility groups in Fusarium oxysporum: Supplement (1999). Phytoparasitica 27:273-277.

20. Katan, T., Katan, J., Gordon, T. R., and Pozniak, D. 1994. Physiologic races and vegetative compatibility groups of Fusarium oxysporum f. sp. melonis in Israel. Phytopathology 84:153-157.

21. Kistler, H. C. 1997. Genetic diversity in the plant-pathogenic fungus Fusarium oxysporum. Phytopathology 87:474-479.

22. Kistler, H. C., Alabouvetter, C., Baayen, R. P., Bentley, S., Brayford, D., Coddington, A. Correll, J., Daboussi, M.-J., Elias, K., Fernandez, D., Gordon, T. R., Katan, T., Kim, H. G., Leslie, J. F., Martyn, R. D., Migheli, Q., Moore, N. Y., O'Donnell, K., Ploetz, R. C., Rutherford, M. A., Summerell, B Waalwijk, C., and Woo, S. 1998. Systematic numbering of vegetative compatibility groups in the plant pathogenic fungus Fusarium oxysporum. Phytopathology 88:30-32.

23. Koenig, R. D., Ploetz, R. C., and Kistler, H. C. 1997. Fusarium oxysporum f. sp. cubense consists of a small number of divergent and globally distributed clonal lineages. Phytopathology 87:915-923.

24. Leslie, J. F. 1990. Genetic exchange within sexual and asexual populations of the genus Fusarium. Pages 37-48 in: Fusarium Wilt of Banana. R. C. Ploetz, ed. American Phytopathological Society Press, St. Paul, MN.

25. Leslie, J. F. 1993. Vegetative compatibility in fungi. Annu. Rev. Phytopathol. 31:127-151.

26. Link, G. K. K., and Bailey, A. A. 1926. Fusaria causing bulb rot of onions. J. Agric. Res. 33:929-952.

27. Löffler, H. J. M., and Rumine, P. 1991. Virulence and vegetative compatibility of Dutch and Italian isolates of Fusarium oxysporum f. sp. lilii. J. Phytopathol. 132:1220

28. Nelson, P. E., Toussoun, T. A., and Marasas, W. F. O. 1983. Fusarium species: An Illustrated Manual for Identification. Pennsylvania State University Press, University Park.

29. Ploetz, R. C. 1990. Population biology of Fusarium oxysporum f. sp. cubense. Pages 63-76 in: Fusarium Wilt of Banana. R. C. Ploetz, ed. American Phytopathological Society Press, St. Paul, MN.

30. Ploetz, R. C., and Shepard, E. S. 1989 Fusarial wilt of banana in Florida. Mycol. Res. 93:242-245.

31. Puhalla, J. E. 1985. Classification of strains of Fusarium oxysporum on the basis of vegetative compatibility. Can. J. Bot. 63:179183.

32. Puhalla, J. E., and Spieth, P. T. 1983. Heterokaryosis in Fusarium moniliforme. Exp. Mycol. 7:328-335.

33. Schwartz, H. F., and Bartolo, M. E. 1995 Colorado Onion Production and Integrated Pest Management. Bull. 547A Coop. Ext. Fort Collins, CO.

34. Schwartz, H. F., Bartolo, M. E., and Schweissing, F. C. 1991. Onion disease management-environmental damage study. Pages 32-37 in: Natl. Onion Res. Conf. Proc. Savannah, GA.

35. Schwartz, H. F., and Mohan, S. K., eds. 1995 Compendium of Onion and Garlic Diseases. American Phytopathological Society Press, 
St. Paul, MN.

36. Swift, C. E. 2001. Fusarium oxysporum f. sp. cepae, the causal agent of Fusarium basal rot of onion: Biology, epidemiology and management. PhD thesis. Colorado State University, Fort Collins.

37. Wickliffe, E. 2001. Characterization of Fusarium oxysporum f. sp. phaseoli and betae in dry beans (Phaseolus vulgaris L.) and sugar beet (Beta vulgaris L.) by pathogenicity and vegetative compatibility grouping. MS thesis. Colorado State University, Fort Collins.

38. Woo, S. L., Zoina, A., Del Sorbo, G., Lorito, M., Nanni, B., Scala, F., and Noviello, C. 1996. Characterization of Fusarium oxy- sporum f. sp. phaseoli by pathogenic races, VCGs, RFLPs and RAPD. Phytopathology 86:966-973.

39. Yoo, S. J., Watanabe, H., Kobayashi, K., Ogoshi, A., and Kodama, F. 1993. Vegetative compatibility grouping of formae speciales of

Fusarium oxysporum pathogenic to the Liliaceae. Ann. Phytopathol. Soc. Jpn. 59:3-9. 